\title{
AVALIAÇÃO DAS HABILIDADES PREDITORAS MATEMÁTICAS NAS SÉRIES INICIAIS DO ENSINO FUNDAMENTAL: UMA REVISÃO INTEGRATIVA DA LITERATURA
}

\author{
Edvaldo Alves de Moraes $^{1}$ \\ Fabrício Bruno Cardoso ${ }^{2}$ \\ Lígia Serrano Lopes ${ }^{3}$
}

RESUMO: Este estudo, cujos pressupostos teóricos se alicerçam nas ciências cognitivas e nos estudos da Neuropsicopedagogia, teve como objetivo desenvolver, a partir da revisão de literatura integrativa, uma análise sobre o aporte de instrumentos de triagem e de avaliação acerca das habilidades matemáticas preditoras ou essenciais a serem desenvolvidas nas Séries Iniciais do Ensino Fundamental, momento escolar crucial para embasar pressupostos nesta área de conhecimento cujas dificuldades de aprendizagem se fazem notórias. Os resultados revelaram não somente o quanto desafiador é este cenário, pois há carência de materiais ou instrumentos validados no nosso país a fim de impulsionar a aprendizagem matemática nas Séries Iniciais como também evidenciaram a necessidade de aprofundamento e impulso de estudos que contribuam e elevem a cientificidade deste tema ainda pouco explorado no Brasil.

Palavras-chaves: Avaliação matemática. Habilidades preditoras matemáticas. Neuropsicopedagogia.

ABSTRACT: This study, whose theoretical assumptions are based on cognitive sciences and studies of Neuropsychopedagogy, aimed to develop, from the integrative literature review, an analysis of the contribution of screening and assessment instruments about predictive or essential mathematical skills. be developed in the Initial Grades of Elementary School, a crucial school moment to support assumptions in this area of knowledge whose learning difficulties are notorious. The results revealed not only how challenging this scenario is, as there is a lack of validated materials or instruments in our country in order to boost mathematics learning in the Initial Grades, but also highlighted

\footnotetext{
${ }^{1}$ Mestrado em Docência para a Educação Básica pela Universidade Estadual Paulista -Júlio de Mesquita Filho; Especialização em Neuropsicopedagogia Institucional e Educação Especial Inclusiva pela Faculdade Censupeg; Pesquisador do Laboratório de Inovações Educacionais e Estudos Neuropsicopedagógicos da Faculdade CENSUPEG (LIEENP/CENSUPEG)

${ }^{2}$ Doutorado em Ciências Biológicas (Biofísica) na Universidade Federal do Rio de Janeiro; Líder do Laboratório de Inovações Educacionais e Estudos Neuropsicopedagógicos da Faculdade CENSUPEG (LIEENP/CENSUPEG); Núcleo de Divulgação Científica e Ensino de Neurociências (NuDCEN/UFRJ).

3 Especialização em Neuropsicopedagogia Institucional e Educação Especial Inclusiva pela Faculdade Censupeg; Pesquisadora do Laboratório de Inovações Educacionais e Estudos Neuropsicopedagógicos da Faculdade CENSUPEG (LIEENP/CENSUPEG)
} 
the need to deepen and promote studies that contribute to and elevate scientificity. this theme is still little explored in Brazil.

Keywords: Mathematical assessment. Predictive Math Skills. Neuropsychopedagogy.

\section{INTRODUÇÃO}

Pesquisas apontam que cerca de $78 \%$ dos pedidos de avaliações multidisciplinares correspondem às dificuldades de aprendizagem em leitura, escrita e matemática (ANDRADE; CASTANHO, 2014). Especialmente no que tange à aprendizagem matemática, a ANA (Avaliação Nacional de Alfabetização) - em amostra aplicada em 2016 com de 2 milhões de alunos concluintes do 3..$^{\circ}$ ano do Ensino Fundamental - indicou que $54,46 \%$ dos estudantes tiveram desempenho abaixo do adequado em Matemática, ou seja, incapazes de efetuar adição com duas parcelas e reagrupamento ou mesmo associar valor monetário à quantidade de cédulas e moedas correspondentes.

Estudos sugerem que estas dificuldades possam ocorrer por mal-entendidos sobre os conceitos básicos como o valor de posição ou devido ao ensino da Matemática ter sido realizado de forma abstrata, focado em procedimentos e com pouco significado para eles, parecendo uma lista de regras com pouca relevância para as situações da vida real. Frequentemente, essas crianças desenvolverão ansiedade matemática e medo de formularem resposta errada, fato que leva os estudantes a com siderarem a disciplina “difícil”, ou seja, criam-se bloqueios para acessá-la.

Ademais, o ensino da Matemática básica torna-se grande desafio proposto pelo PNA que define a numeracia não só como a habilidade de usar números para contar, mas se refere antes à habilidade de usar a compreensão e as habilidades matemáticas para fins de solucionar problemas e encontrar respostas para as demandas da vida cotidiana. Como mencionado anteriormente, a aprendizagem Matemática é gradual e cumulativa, portanto, aprender e compreender o pressupostos é essencial. Se uma criança fica para trás ou em defasagem em um conteúdo matemático devido à falta de compreensão, passar para tópicos mais avançados continuará sendo um desafio.

Embora, atualmente, não possamos afirmar que os mesmos alunos que se apresentam desempenho insatisfatório em Matemática nas Séries Iniciais do Ensino Fundamental provavelmente permanecerão com desempenho abaixo ou apresentando 
dificuldades em Matemática pelo resto de suas carreiras acadêmica, há evidências de que os conceitos numéricos que as crianças adquirem na primeira infância estabelecem o alicerce para a aquisição posterior de conceitos matemáticos avançados, assim como que o sucesso ou o fracasso na aquisição de conceitos numéricos iniciais influencia o interesse e a confiança que os alunos trazem para novas tarefas matemáticas e podem alterar fundamentalmente o sucesso de um aluno nesta área de conhecimento ao longo das séries do Ensino Fundamental. Assim, torna-se imprescindível identificar os aspectos mais salientes da compreensão, da defasagem ou do domínio das relações e das operações numéricas básicas que um estudante apresenta por meio de medidas de triagem potenciais com intuito de aferir e identificar de maneira precoce as possíveis dificuldades de aprendizagem na da Matemática.

\section{METODOLOGIA}

O presente estudo desenvolveu-se a partir da revisão de literatura integrativa, ou seja, de pesquisa a partir de banco de dados de literatura publicada sobre tema específico e com ênfase na metanálise (SAMPAIO; MANCINI, 2007). A partir deste estudos e seleção sobre o objeto de estudo presente, foram descartadas delimitações diversas que não

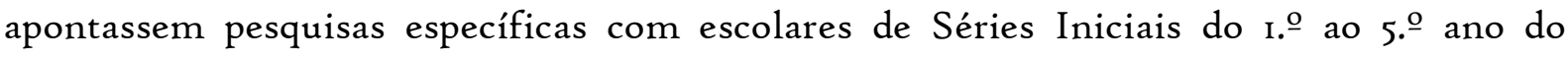
Ensino Fundamental no sistema educacional brasileiro.

Dessa forma, nos meses de julho a setembro do ano de 202I, foram realizadas buscas por gêneros textuais científicos que abordassem os temas relacionados à avaliação das habilidades essenciais para a aprendizagem de Matemática nas Séries Iniciais do Ensino Fundamental, bem como instrumentos de triagem e de avaliação já validados no Brasil. A revisão literária embasou-se em pressupostos teóricos das ciências cognitivas e em estudos da Neuropsicopedagogia. Além disso, a pesquisa pautou-se em Bases de Dados nacionais e internacionais como Scientific Electronic Library Online (SciELO), Periódicos Eletrônicos de Psicologia (PePSIC), Google Acadêmico (GA) e nos periódicos disponíveis na Biblioteca Digital Brasileira de Teses e Dissertações (BDTD).

Destacamos que foram utilizados, com base nas diferenças reconhecidas em cada mecanismo de busca textual, os seguintes descritores: Avaliação de habilidades matemáticas em Séries Iniciais e validação de instrumentos de avaliação matemática. 
Foram usados como critérios de seleção dos textos pesquisados os seguintes pressupostos: I) apresentassem referência direta ao tema "Instrumentos de triagem e avaliação de habilidades essenciais necessárias para a aprendizagem matemática nas Séries Iniciais"; 2) publicados entre o período de 2015 a 2020;3) disponíveis em línguas portuguesa e/ou inglesa; 4) contextualizassem a realidade brasileira; 5) possuíssem referencial teórico em relação à existência de testes validados para a população brasileira (escolares das Séries Iniciais do Ensino Fundamental) para avaliação das habilidades essenciais matemáticas; 6) elencassem os instrumentos validados no Brasil para tal objetivo; e 7) fossem classificados com relevância em citações de trabalhos científicos. Logo, foram descartados para análise todos os referenciais textuais que não apresentavam dados de comprovação científica; publicados antes de 2015 ou que não apontassem o estudo completo disponível. Quanto aos raros instrumentos brasileiros disponíveis para a avaliação das habilidades matemáticas voltados ao público-alvo em questão, quando coincidiram em duas ou mais fontes de citação, foram contadas apenas única vez.

\section{RESULTADOS}

Dentre os suportes de textos ou objetos aqui pesquisados (artigos, dissertações de mestrado profissional, pesquisas e teses), é notória a presença de estudos que enfatizam e comprovam a existência de dificuldades na aprendizagem matemática de escolares das Séries Inicias do EF, porém sem detalhamento quanto aos instrumentos validados para intervenção necessária. Além disso, enfatiza-se a necessidade da formação inicial e continuada de professores e demais causas relacionadas às dificuldades e ao baixo desempenho matemático neste ciclo escolar.

No total, dos ioo (cem) textos/estudos levantados, foram descartados 90 (noventa) após a leitura do título, dos respectivos resumos e do desenvolvimento do corpo de texto, conforme os critérios de seleção supracitados. Portanto, foram selecionados, ao final da busca e pesquisa avançada, ıo (dez) aportes teóricos que investigam como avaliar as habilidades essenciais matemáticas, bem como os instrumentos/testes utilizados para tal levantamento. Os objetivos, a descrição dos estudos pertinentes levantados na presente pesquisa e as conclusões estão apresentados no Quadro I abaixo: 
Quadro I - Caracterização dos aportes teóricos que investigam instrumentos de avaliação das habilidades matemáticas nas Séries Iniciais do EF no Brasil

\begin{tabular}{|c|c|c|c|c|}
\hline $\begin{array}{l}\text { SUPORTE DE } \\
\text { TEXTO/ANO }\end{array}$ & AUTORES & $\begin{array}{l}\text { DESCRIÇÃO } \\
\text { DO ESTUDO }\end{array}$ & $\begin{array}{c}\text { FAIXA } \\
\text { ETÁRIA }\end{array}$ & $\begin{array}{l}\text { RESULTAD } \\
\text { OS }\end{array}$ \\
\hline $\begin{array}{l}\text { Avaliação } \\
\text { Psicológica, 20(I), } \\
\text { pp. 23-32. 2021. }\end{array}$ & $\begin{array}{l}\text { DIAS, Janaína } \\
\text { G. R. et al. }\end{array}$ & $\begin{array}{l}\text { Revisão de } \\
\text { pesquisas que } \\
\text { avaliam o } \\
\text { desempenho e a } \\
\text { compreensão da } \\
\text { Matemática, } \\
\text { por meio de } \\
\text { instrumentos } \\
\text { psicológicos e } \\
\text { neuropsicológic } \\
\text { os publicadas } \\
\text { entre 2or3 a 2org } \\
\text { visando } \\
\text { oferecer } \\
\text { subsídios para } \\
\text { que psicólogos e } \\
\text { educadores }\end{array}$ & $\begin{array}{l}\text { Predomínio de } \\
\text { estudos que } \\
\text { investigam } \\
\text { apenas crianças } \\
\text { na faixa etária } \\
\text { de } 3 \text { a I2 anos } \\
(70,7 \%) \text {. }\end{array}$ & $\begin{array}{l}\text { Comprovou- } \\
\text { se, na revisão } \\
\text { literária, que o } \\
\text { subteste } \\
\text { Aritmética da } \\
\text { Escala de } \\
\text { Inteligência } \\
\text { Wechsler para } \\
\text { Crianças } \\
\text { (WISC-III) } \\
\text { foi o } \\
\text { instrumento } \\
\text { com uso mais } \\
\text { frequente, } \\
\text { seguido do } \\
\text { subteste } \\
\text { Aritmética do }\end{array}$ \\
\hline & & $\begin{array}{l}\text { avaliem o } \\
\text { repertório } \\
\text { matemático em } \\
\text { suas práticas } \\
\text { profissionais. }\end{array}$ & & $\begin{array}{l}\text { Teste de } \\
\text { Desempenho } \\
\text { Escolar (TDE- } \\
\text { I) e do } \\
\text { subteste } \\
\text { Cálculo da } \\
\text { Bateria } \\
\text { Woodcock- } \\
\text { Johnson (WJ- } \\
\text { III), todos são } \\
\text { comercializado } \\
\text { s no Brasil, } \\
\text { sendo apenas a } \\
\text { escala WISC } \\
\text { restrita a } \\
\text { psicólogos. } \\
\text { Detectou-se a } \\
\text { ausência da } \\
\text { avaliação de } \\
\text { outras áreas do } \\
\text { conhecimento } \\
\text { matemático, } \\
\text { como a Álge- }\end{array}$ \\
\hline
\end{tabular}




\begin{tabular}{|c|c|c|c|c|}
\hline & & & & $\begin{array}{l}\text { bra e a } \\
\text { Geometria. }\end{array}$ \\
\hline $\begin{array}{l}\text { Revista } \\
\text { Psicopedagogia, } \\
\text { vol. 37, núm. I13, p. } \\
\text { 168-82, 2020. }\end{array}$ & $\begin{array}{l}\text { CIASCA, } \\
\text { Sylvia. } \\
\text { DORES, Sônia } \\
\text { M das. }\end{array}$ & $\begin{array}{l}\text { Artigo que } \\
\text { descreve a } \\
\text { tradução e a } \\
\text { adaptação do } \\
\text { BAT-MAT } \\
\text { (Bateria de } \\
\text { Aferição de } \\
\text { Competências } \\
\text { Matemáticas), } \\
\text { cuja aplicação } \\
\text { permite aferir } \\
\text { desempenho e } \\
\text { planejar } \\
\text { intervenções } \\
\text { necessárias } \\
\text { sobre conteúdos } \\
\text { sugeridos nos } \\
\text { PCNs. }\end{array}$ & $\begin{array}{l}\text { Aplicado em I6 } \\
\text { estudantes } \\
\text { entre } 8 \text { e II } \\
\text { anos, de ambos } \\
\text { os sexos e com } \\
\text { desenvolvimen } \\
\text { to típico, sem } \\
\text { histórico de } \\
\text { repetência nem } \\
\text { dificuldades de } \\
\text { aprendizagem } \\
\text { do EF de } \\
\text { escolas } \\
\text { públicas e } \\
\text { privadas. }\end{array}$ & $\begin{array}{l}\text { Após versão } \\
\text { traduzida para } \\
\text { o português do } \\
\text { Brasil, } \\
\text { verificou-se } \\
\text { dificuldade em } \\
\text { todas as } \\
\text { competências } \\
\text { avaliadas, o } \\
\text { que corrobora } \\
\text { com os } \\
\text { resultados das } \\
\text { avaliações } \\
\text { oficiais (SAEB } \\
\text { e PISA) como } \\
\text { reconhecer e } \\
\text { escrever } \\
\text { símbolos } \\
\text { matemáticos; } \\
\text { realizar } \\
\text { operações que } \\
\text { envolvam } \\
\text { cálculo mental; } \\
\text { compreender } \\
\text { conceitos } \\
\text { matemáticos } \\
\text { com relações } \\
\text { de grandeza, } \\
\text { lateralidade, } \\
\text { posicionament } \\
\text { o e } \\
\text { classificação; } \\
\text { executar as } \\
\text { operações e } \\
\text { fazer cálculos } \\
\text { numéricos. }\end{array}$ \\
\hline $\begin{array}{l}\text { Dissertação } \\
\text { Mestrado em } \\
\text { Psicologia } \\
\text { Cognitiva (UFPE } \\
\text {-2020). }\end{array}$ & $\begin{array}{l}\text { SANTANA, } \\
\text { Alanny Nunes } \\
\text { de. }\end{array}$ & $\begin{array}{l}\text { Estudo sobre as } \\
\text { relações entre } \\
\text { FE e } \\
\text { desempenho } \\
\text { matemático. } \\
\text { Utilizou-se os }\end{array}$ & $\begin{array}{l}\text { Participaram } \\
\text { Io estudantes } \\
\text { de escolas } \\
\text { públicas e } \\
\text { privadas de } \\
\text { Recife(PE), }\end{array}$ & $\begin{array}{l}\text { Comprovou-se } \\
\text { o valor } \\
\text { preditivo das } \\
\text { FE no } \\
\text { desempenho } \\
\text { em }\end{array}$ \\
\hline
\end{tabular}




\begin{tabular}{|c|c|c|c|c|}
\hline & & $\begin{array}{l}\text { instrumentos } \\
\text { Mini-Exame de } \\
\text { Estado Mental } \\
\text { (MEEM), } \\
\text { Coruja - } \\
\text { PROMAT; } \\
\text { NEUPSILIN- } \\
\text { INF e outros. }\end{array}$ & $\begin{array}{l}\text { ambos os sexos } \\
\text { e de } 8 \text { a } 12 \text { anos. }\end{array}$ & $\begin{array}{l}\text { Matemática e } \\
\text { a necessidade } \\
\text { de protocolos } \\
\text { de intervenção } \\
\text { que avaliem } \\
\text { resultados a } \\
\text { partir das } \\
\text { intervenções } \\
\text { na FE. }\end{array}$ \\
\hline $\begin{array}{l}\text { VII Congresso } \\
\text { Nacional de } \\
\text { Educação } \\
\text { (CONEDU)- } \\
\text { (AL; 2020) }\end{array}$ & $\begin{array}{l}\text { SANTOS, } \\
\text { Inara L. C. dos. } \\
\text { et al. }\end{array}$ & $\begin{array}{l}\text { Pesquisa } \\
\text { bibliográfica } \\
\text { para análise de } \\
\text { instrumentos } \\
\text { de avaliação } \\
\text { matemática no } \\
\text { I. o ciclo do EF. }\end{array}$ & $\begin{array}{l}\text { Estudantes de } 6 \\
\text { a } 8 \text { anos. }\end{array}$ & $\begin{array}{l}\text { Foram } \\
\text { identificados } \\
\text { apenas } \\
\text { quatro } \\
\text { instrumentos } \\
\text { (Teste de } \\
\text { Desempenho } \\
\text { Escolar } \\
\text { (TDE), Teste } \\
\text { de } \\
\text { Desempenho } \\
\text { Escolar - } \\
\text { Segunda } \\
\text { Edição (TDE } \\
\text { II), Escala de } \\
\text { Inteligência } \\
\text { Wechsler para } \\
\text { crianças - } 4 .^{\text {a }} \\
\text { Edição } \\
\text { (WISC-IV) e } \\
\text { Prova de } \\
\text { Aritmética } \\
\text { (PA), o que } \\
\text { aponta para a } \\
\text { escassez de } \\
\text { pesquisas } \\
\text { voltadas a esta } \\
\text { temática. }\end{array}$ \\
\hline
\end{tabular}




\begin{tabular}{|c|c|c|c|c|}
\hline $\begin{array}{l}\text { Revista Educação } \\
\text { em Foco. Juiz de } \\
\text { Fora, v. 23, n. 2, p. } \\
541^{-567}, 2018 .\end{array}$ & $\begin{array}{l}\text { HENKLEIN, } \\
\text { Marcelo H. O. } \\
\text { GUALBERTO, } \\
\text { Priscila M de } \\
\text { A. } \\
\text { CARMO, João } \\
\text { dos S. }\end{array}$ & $\begin{array}{l}\text { Foram descritos } \\
\text { os resultados da } \\
\text { aplicação de } \\
\text { Bateria de } \\
\text { Testes Fioraneli } \\
\text { et al (2oII) para } \\
\text { avaliar e } \\
\text { mapear } \\
\text { habilidades } \\
\text { numéricas } \\
\text { básicas para } \\
\text { estudantes das } \\
\text { Séries Iniciais } \\
\text { do Ensino } \\
\text { Fundamental. }\end{array}$ & $\begin{array}{l}\text { Alunos de } \\
\text { escola pública } \\
\text { de } 7 \text { a II anos. }\end{array}$ & $\begin{array}{l}\text { Foram } \\
\text { avaliadas } 63 \\
\text { tipos de } \\
\text { habilidades } \\
\text { matemáticas } \\
\text { básicas } \\
\text { programadas } \\
\text { em software } \\
\text { ProgMIS que } \\
\text { concluiu maior } \\
\text { incidência de } \\
\text { erros nas } \\
\text { habilidades de } \\
\text { realizar } \\
\text { operação } \\
\text { aritmética e } \\
\text { ordenar } \\
\text { conjuntos. } \\
\text { Também foi } \\
\text { identificada a } \\
\text { falta de } \\
\text { compreensão } \\
\text { da instrução } \\
\text { dada e a } \\
\text { necessidade de } \\
\text { pesquisas } \\
\text { futuras que } \\
\text { aprimorem } \\
\text { testes e } \\
\text { intervenções. }\end{array}$ \\
\hline $\begin{array}{l}\text { Dissertação } \\
\text { Mestrado "Ensino } \\
\text { da Matemática nas } \\
\text { Séries Iniciais: } \\
\text { dificuldades e } \\
\text { desafios". (UFAL, } \\
\text { 2018) }\end{array}$ & $\begin{array}{l}\text { NEVES, das } \\
\text { Tony Fabio } \\
\text { Silva. }\end{array}$ & $\begin{array}{l}\text { O trabalho } \\
\text { evidenciou as } \\
\text { dificuldades na } \\
\text { educação } \\
\text { matemática, } \\
\text { possíveis causas } \\
\text { relacionadas } \\
\text { tanto à } \\
\text { formação de } \\
\text { professores } \\
\text { quanto às } \\
\text { dificuldades dos } \\
\text { alunos. } \\
\text { Sugestões de } \\
\text { atividades }\end{array}$ & $\begin{array}{l}\text { Alunos do } 5.9 \\
\text { ano da rede } \\
\text { municipal de } \\
\text { Palmeiras dos } \\
\text { índios (AL) e } \\
40 \text { professores } \\
\text { das turmas dos } \\
5 .^{\circ} \text { anos. }\end{array}$ & $\begin{array}{l}\text { Dificuldade } \\
\text { encontrada por } \\
\text { pedagogos ao } \\
\text { lecionarem } \\
\text { ainda de forma } \\
\text { tradicional a } \\
\text { Matemática. }\end{array}$ \\
\hline
\end{tabular}




\begin{tabular}{|c|c|c|c|c|}
\hline & & $\begin{array}{l}\text { dinâmica/ } \\
\text { lúdicas para } \\
\text { ensino- } \\
\text { aprendizagem. }\end{array}$ & & \\
\hline $\begin{array}{l}\text { Revista } \\
\text { Psicopedagogia; } \\
\text { 34(104): 148-57, } \\
2017 .\end{array}$ & $\begin{array}{l}\text { PIRES, Ariane } \\
\text { B. C. } \\
\text { SIMÃO, } \\
\text { Adriana N. de } \\
\text { Paula. }\end{array}$ & $\begin{array}{l}\text { Foi utilizado o } \\
\text { Instrumento } \\
\text { NEUPSILIN- } \\
\text { INF, o qual } \\
\text { utiliza } \\
\text { provas de } \\
\text { linguagem, } \\
\text { memória, } \\
\text { atenção, } \\
\text { orientação } \\
\text { espaço- } \\
\text { temporal, } \\
\text { percepção, } \\
\text { habilidade } \\
\text { aritmética, } \\
\text { entre outros. }\end{array}$ & $\begin{array}{l}\text { Participaram 2I } \\
\text { alunos de } \\
\text { ambos os sexos } \\
\text { do I. } \text { ao } 3 .^{\circ} \text { ano } \\
\text { do EFAI de } \\
\text { escola estadual } \\
\text { de Campinas } \\
\text { (SP), sendo II } \\
\text { sem } \\
\text { dificuldade de } \\
\text { aprendizagem e } \\
\text { Io com. }\end{array}$ & $\begin{array}{l}\text { Os resultados } \\
\text { demonstraram } \\
\text { ser possível } \\
\text { confirmar } \\
\text { que há } \\
\text { diferença nas } \\
\text { habilidades } \\
\text { cognitivas e } \\
\text { funções } \\
\text { executivas } \\
\text { avaliadas pelo } \\
\text { instrumento } \\
\text { NEUPSILIN- } \\
\text { Inf. O } \\
\text { resultado } \\
\text { inferior nos } \\
\text { testes de } \\
\text { habilidades } \\
\text { aritméticas } \\
\text { corrobora com } \\
\text { outros estudos } \\
\text { que apontam a } \\
\text { existência de } \\
\text { relações entre } \\
\text { linguagem e } \\
\text { aprendizagem } \\
\text { matemática. }\end{array}$ \\
\hline $\begin{array}{l}\text { Tese de Doutor } \\
\text { em Distúrbios do } \\
\text { desenvolvimento. } \\
\text { Universidade } \\
\text { Presbiteriana } \\
\text { Mackenzie. São } \\
\text { Paulo. 2oi6. }\end{array}$ & $\begin{array}{l}\text { PAZETO, } \\
\text { Talita de C. B. }\end{array}$ & $\begin{array}{l}\text { Foi investigado } \\
\text { como a } \\
\text { avaliação de } \\
\text { habilidades } \\
\text { cognitivas na } \\
\text { pré-escola e nos } \\
\text { primeiros anos } \\
\text { do EF são } \\
\text { essenciais para } \\
\text { identificarem as } \\
\text { habilidades } \\
\text { preditoras na } \\
\text { aprendizagem } \\
\text { de necessárias }\end{array}$ & $\begin{array}{l}\text { Foram } \\
\text { avaliados entre } \\
2012 \text { e } 2014, \\
\text { cerca de 7I } \\
\text { escolares de } 4 \text { a } \\
6 \text { anos de } \\
\text { escola } \\
\text { particular de } \\
\text { São Paulo. }\end{array}$ & $\begin{array}{l}\text { Dentre os } \mathrm{I} 3 \\
\text { instrumentos } \\
\text { usados para } \\
\text { avaliar as } \\
\text { funções } \\
\text { executivas, } \\
\text { destaca-se, } \\
\text { para a } \\
\text { aprendizagem } \\
\text { matemática, a } \\
\text { Prova } \\
\text { Aritmética } \\
\text { (PA) para I. } \\
\text { ano com }\end{array}$ \\
\hline
\end{tabular}




\begin{tabular}{|c|c|c|c|c|}
\hline & & $\begin{array}{l}\text { na leitura, } \\
\text { escrita e } \\
\text { matemática. }\end{array}$ & & $\begin{array}{l}\text { ênfase no } \\
\text { processamento } \\
\text { numérico e } \\
\text { cálculo. } \\
\text { Contém } 6 \\
\text { subtestes cuja } \\
\text { análise de } \\
\text { erros indica } \\
\text { quais } \\
\text { habilidades } \\
\text { matemáticas } \\
\text { estão } \\
\text { preservadas ou } \\
\text { alteradas. }\end{array}$ \\
\hline $\begin{array}{l}\text { Psicologia Escolar } \\
\text { e Educacional, SP. } \\
\text { Volume } 20, \text { N.3, } \\
\text { setembro/dezemb } \\
\text { ro: } 465-473,2016 \text {. }\end{array}$ & $\begin{array}{l}\text { SANTOS, dos } \\
\text { Acácia A. A. } \\
\text { FERNANDES, } \\
\text { Eliane S. de O. }\end{array}$ & $\begin{array}{l}\text { Estudo } \\
\text { realizado com } \\
485 \text { crianças de } \\
\text { ambos os sexos } \\
\text { das } 5 \text { regiões do } \\
\text { Brasil. Foram } \\
\text { utilizados } \\
\text { Escala de } \\
\text { Avaliação da } \\
\text { Escrita - } \\
\text { EAVE, Teste } \\
\text { de Cloze e } \\
\text { Teste de } \\
\text { Desempenho } \\
\text { Escolar - TDE } \\
\text { para verificar o } \\
\text { valor preditivo } \\
\text { destes para o } \\
\text { desempenho } \\
\text { escolar. }\end{array}$ & $\begin{array}{l}\text { Estudantes de } 6 \\
\text { a } 12 \text { anos do } 2.9 \\
\text { ao } 5 .{ }^{\circ} \text { ano do } \\
\text { EF. }\end{array}$ & $\begin{array}{l}\text { Comprovou-se } \\
\text { o quanto o } \\
\text { desempenho } \\
\text { destes testes } \\
\text { que avaliam a } \\
\text { compreensão } \\
\text { de leitura e de } \\
\text { escrita podem } \\
\text { ser preditivos } \\
\text { do } \\
\text { desempenho } \\
\text { escolar em } \\
\text { leitura, escrita } \\
\text { e aritmética: } \\
40 \% \text { da } \\
\text { variação acerca } \\
\text { do } \\
\text { desempenho } \\
\text { em aritmética } \\
\text { no TDE } \\
\text { podem ser } \\
\text { previstas pela } \\
\text { compreensão } \\
\text { de leitura e } \\
\text { predizer em } \\
21 \% \text { no } \\
\text { desempenho } \\
\text { escolar em } \\
\text { Aritmética. }\end{array}$ \\
\hline $\begin{array}{l}\text { Revista } \\
\text { Neuropsicologia }\end{array}$ & $\begin{array}{l}\text { FANTE V. V.; } \\
\text { HOFNHEIZ }\end{array}$ & $\begin{array}{l}\text { Estudo para } \\
\text { investigar }\end{array}$ & $\begin{array}{l}\text { Participaram } \\
\text { III estudantes }\end{array}$ & $\begin{array}{l}\text { Conclui-se que } \\
\text { Subteste }\end{array}$ \\
\hline
\end{tabular}




\begin{tabular}{|c|c|c|c|c|}
\hline $\begin{array}{l}\text { Latinoamericana, } \\
\text { vol. 8, núm. 2, pp. } \\
\text { ı-26, 2016. }\end{array}$ & $\begin{array}{l}\text { G. C.; } \\
\text { MILNITSY S. } \\
\text { L.; } \\
\text { PAZ F.R. }\end{array}$ & $\begin{array}{l}\text { evidências de } \\
\text { validade } \\
\text { do Subteste } \\
\text { Aritmética do } \\
\text { Teste de } \\
\text { Desempenho } \\
\text { Escolar- } \\
\text { Segunda Edição } \\
\text { (TDE-II), à luz } \\
\text { de reflexões } \\
\text { sobre a relação } \\
\text { entre a } \\
\text { Aritmética com } \\
\text { FE e } \\
\text { habilidades } \\
\text { linguísticas. }\end{array}$ & $\begin{array}{l}\text { do I. } .^{\circ} \text { ao } 9 .^{\circ} \text { ano } \\
\text { do EF de } \\
\text { escolas } \\
\text { públicas e } \\
\text { privadas de } \\
\text { Porto Alegre } \\
\text { (RS). A } \\
\text { amostra contou } \\
\text { com ro a I4 } \\
\text { estudantes para } \\
\text { cada ano } \\
\text { escolar, } \\
\text { pareados em } \\
\text { relação ao sexo, } \\
\text { sendo } \\
\text { metade da } \\
\text { escola pública. }\end{array}$ & $\begin{array}{l}\text { Aritmética do } \\
\text { TDE-II } \\
\text { apresenta } \\
\text { evidências de } \\
\text { validade } \\
\text { convergente } \\
\text { adequadas e } \\
\text { caracteriza-se } \\
\text { como um } \\
\text { instrumento } \\
\text { potencial para } \\
\text { avaliação do } \\
\text { desempenho } \\
\text { escolar tanto } \\
\text { em contexto } \\
\text { escolar como } \\
\text { no clínico. } \\
\text { Também } \\
\text { destacou a } \\
\text { carência de } \\
\text { instrumentos } \\
\text { que } \\
\text { apresentam } \\
\text { estudos de } \\
\text { propriedades } \\
\text { psicométricas } \\
\text { e validação } \\
\text { para a } \\
\text { população } \\
\text { brasileira. }\end{array}$ \\
\hline $\begin{array}{l}\text { Tese de Doutor } \\
\text { em Educação. } \\
\text { Universidade } \\
\text { Federal do Paraná, } \\
2016 .\end{array}$ & $\begin{array}{l}\text { PETRONZEL } \\
\text { LI, Vera L. L. }\end{array}$ & $\begin{array}{l}\text { Foram } \\
\text { investigadas as } \\
\text { políticas } \\
\text { educacionais de } \\
\text { avalição } \\
\text { externa da } \\
\text { escola } \\
\text { (PISA/OCDE) } \\
\text { com ênfase na } \\
\text { literacia } \\
\text { matemática e } \\
\text { como indicar } \\
\text { caminhos para } \\
\text { melhorar a } \\
\text { educação } \\
\text { matemática no }\end{array}$ & $\begin{array}{l}\text { Educação } \\
\text { Básica }\end{array}$ & $\begin{array}{l}\text { Dentre os } \mathrm{I} 3 \\
\text { instrumentos } \\
\text { usados para } \\
\text { avaliar as } \\
\text { funções } \\
\text { executivas, } \\
\text { destaca-se, } \\
\text { para a } \\
\text { aprendizagem } \\
\text { matemática, a } \\
\text { Prova } \\
\text { Aritmética } \\
\text { (PA) para I. } \\
\text { ano com } \\
\text { ênfase no } \\
\text { processamento }\end{array}$ \\
\hline
\end{tabular}




\begin{tabular}{|l|l|l|l|}
\hline & $\begin{array}{l}\text { desenvolviment } \\
\text { o das } \\
\text { competências } \\
\text { essenciais. }\end{array}$ & $\begin{array}{l}\text { numérico e } \\
\text { cálculo. } \\
\text { Contém 6 } \\
\text { subtestes cuja } \\
\text { análise de } \\
\text { erros indica } \\
\text { quais } \\
\text { habilidades } \\
\text { matemáticas } \\
\text { estão } \\
\text { preservadas ou } \\
\text { alteradas. }\end{array}$ \\
\hline
\end{tabular}

Fonte: Elaborado pelos autores.

Já, no Quadro 2, pode-se observar os principais instrumentos que foram usados nos estudos supracitados e validados no contexto de amostra brasileira a fim de avaliar as habilidades preditoras na aprendizagem matemática. Destaca-se que são poucas as ferramentas de triagem para identificar alunos em risco de dificuldades matemáticas, principalmente as que abordam uma série de variáveis críticas, incluindo validade preditiva e seleção de conteúdo. Ressalta-se que, ao projetar medidas de identificação precoce em Matemática, uma variável crítica é até que ponto o desempenho nessas medidas se relaciona com o desempenho posterior em Matemática.

Quadro 2 - Descrição dos principais instrumentos de avaliação das habilidades matemáticas nas Séries Iniciais do EF no Brasil

\begin{tabular}{|c|c|c|c|}
\hline INSTRUMENTO & AUTOR & IDADE/USO & $\begin{array}{c}\text { MODO DE } \\
\text { APLICAÇÃO }\end{array}$ \\
\hline $\begin{array}{l}\text { WISC-IV } \\
\text { (Subteste } \\
\text { Aritmética das } \\
\text { Escalas } \\
\text { de Inteligência } \\
\text { Wechsler para } \\
\text { crianças - 4. } \cdot^{\text {a }} \\
\text { Edição). 2013. }\end{array}$ & $\begin{array}{l}\text { WECHSLER, } \\
\text { David. } \\
\text { Adaptação } \\
\text { Brasileira: Fabián } \\
\text { Javier Marín } \\
\text { Rueda; Ana Paula } \\
\text { Porto Noronha; } \\
\text { Fermino Fernandes } \\
\text { Sisto; Acácia } \\
\text { Aparecida Angeli } \\
\text { dos Santos; } \\
\text { Nelimar Ribeiro de } \\
\text { Castro. }\end{array}$ & $\begin{array}{l}\text { De } 6 \text { a ı6 anos } \\
\text { para avaliação do } \\
\text { raciocínio } \\
\text { aritmético e } \\
\text { resolução de } \\
\text { problemas. }\end{array}$ & $\begin{array}{l}\text { Um problema } \\
\text { matemático é lido } \\
\text { pelo examinador e } \\
\text { o aluno tem } \\
\text { 3os para fornecer a } \\
\text { resposta do } \\
\text { problema } \\
\text { oralmente. Não é } \\
\text { permitido o uso de } \\
\text { papel e caneta. O } \\
\text { avaliado ganha um } \\
\text { ponto para cada } \\
\text { resposta correta e a } \\
\text { aplicação é } \\
\text { interrompida após } \\
4 \text { erros } \\
\text { consecutivos. }\end{array}$ \\
\hline
\end{tabular}




\begin{tabular}{|c|c|c|c|}
\hline $\begin{array}{l}\text { TDE II (Subteste } \\
\text { Aritmética Teste } \\
\text { de Desempenho } \\
\text { Escolar - } \\
\text { 2. Edição). 2or6. }\end{array}$ & $\begin{array}{l}\text { STEIN, M. Lilian. } \\
\text { GIACOMONI, } \\
\text { Claudia. } \\
\text { FONSECA, P. } \\
\text { Rochele. }\end{array}$ & $\begin{array}{l}\text { Rastreio } \\
6 \text { a I4 anos } \\
\text { Desenvolvido para } \\
\text { abranger os } 9 \text { anos } \\
\text { do EF (I. }{ }^{\circ} \text { ao } 9 .^{\circ} \\
\text { ano), ou seja, testa } \\
\text { uma nova versão } \\
\text { do subteste de } \\
\text { aritmética do TDE }\end{array}$ & $\begin{array}{l}\text { Versão A: reúne } 37 \\
\text { itens de avaliação } \\
\text { desenvolvidos para } \\
\text { estudantes de I. }{ }^{\circ} \text { a } \\
\text { 5. } \text { ano do EFAI. }^{\text {Esta }} \\
\text { versão inclui itens } \\
\text { iniciais de } \\
\text { processamento } \\
\text { numérico } \\
\text { (contagem, escrita } \\
\text { de números em } \\
\text { formato arábicos, } \\
\text { sequência } \\
\text { numérica, } \\
\text { magnitude } \\
\text { simbólica e } \\
\text { problemas orais } \\
\text { de operações } \\
\text { aritmética } \\
\text { simples), ou seja, } \\
\text { que envolvem as } \\
\text { quatro operações } \\
\text { básicas, escrita de } \\
\text { números decimais, } \\
\text { noções e operações } \\
\text { simples com } \\
\text { frações. Versão B: } \\
\text { de 6. }{ }^{\circ} \text { a } 9 .^{\circ} \text { ano e } \\
\text { inclui cálculos } \\
\text { aritméticos } \\
\text { complexos. } \\
\text { Possibilita } \\
\text { avaliação breve da } \\
\text { aprendizagem e } \\
\text { não diagnostica } \\
\text { transtornos de } \\
\text { aprendizagem. }\end{array}$ \\
\hline $\begin{array}{l}\text { Teste de } \\
\text { Desempenho } \\
\text { Escolar (TDE). } \\
\text { 1994. }\end{array}$ & STEIN, M. Lílian. & $\begin{array}{l}\text { Avaliação dos } \\
\text { domínios de } \\
\text { leitura, escrita e } \\
\text { aritmética para } \\
\text { alunos de } 7 \text { a } 13 \\
\text { anos ou I. a a } 6 .^{\text {a }} \\
\text { série do Ensino }\end{array}$ & $\begin{array}{l}\text { Composto por três } \\
\text { subtestes que } \\
\text { avaliam as } \\
\text { capacidades } \\
\text { básicas para o } \\
\text { desempenho } \\
\text { escolar: leitura, }\end{array}$ \\
\hline
\end{tabular}




\begin{tabular}{|c|c|c|c|}
\hline & & $\begin{array}{l}\text { Fundamental, } \\
\text { podendo ser } \\
\text { aplicado com } \\
\text { algumas reservas } \\
\text { para } 7 .^{\text {a e }} 8 .^{\text {a }} \text { série, } \\
\text { Com a atualização } \\
\text { curricular do EF de } \\
9 \text { anos pela, Lei } \\
\text { n.o ıo.I72, de } 9 \text { de } \\
\text { janeiro de } 200 \text {, foi } \\
\text { atualizado em } \\
\text { versão TED II. }\end{array}$ & $\begin{array}{l}\text { escrita e } \\
\text { aritmética. A } \\
\text { proposta desse } \\
\text { instrumento é que } \\
\text { os subtestes } \\
\text { apresentem uma } \\
\text { escala de itens em } \\
\text { ordem crescente } \\
\text { de dificuldade, os } \\
\text { quais devem ser } \\
\text { apresentados para } \\
\text { as crianças } \\
\text { independente de } \\
\text { sua série. O teste } \\
\text { pode ser } \\
\text { interrompido, } \\
\text { assim que as } \\
\text { questões } \\
\text { apresentadas em } \\
\text { determinado nível } \\
\text { da escala forem } \\
\text { impossíveis de } \\
\text { serem resolvidas } \\
\text { pelo examinando. }\end{array}$ \\
\hline $\begin{array}{l}\text { NEUPSILIN-Inf. } \\
2015 .\end{array}$ & $\begin{array}{l}\text { SALLES, J. F. et } \\
\text { al. }\end{array}$ & $\begin{array}{l}\text { Avaliação de } 8 \\
\text { funções } \\
\text { neuropsicológicas } \\
\text { por meio de } 26 \\
\text { subtestes de } \\
\text { orientação, } \\
\text { atenção, percepção, } \\
\text { memória, } \\
\text { linguagem, } \\
\text { habilidades } \\
\text { visuoconstrutivas, } \\
\text { habilidades } \\
\text { aritméticas e } \\
\text { funções } \\
\text { executivas. } \\
6 \text { a } 9 \text { anos. }\end{array}$ & $\begin{array}{l}\text { Individual, sem } \\
\text { limite de tempo, } \\
\text { sendo que a } \\
\text { maioria das } \\
\text { aplicações leva em } \\
\text { média 5o minutos, } \\
\text { segundo o manual. }\end{array}$ \\
\hline $\begin{array}{l}\text { Prova Aritmética } \\
\text { (PA), 2013. }\end{array}$ & $\begin{array}{l}\text { SEABRA, A.G. et } \\
\text { all. }\end{array}$ & $\begin{array}{l}\text { Para estudantes de } \\
6 \text { a II anos. } \\
\text { Engloba avaliação } \\
\text { de números por } \\
\text { extenso } \\
\text { apresentados }\end{array}$ & $\begin{array}{l}\text { Composto por } 6 \\
\text { subtestes. } \\
\text { I.o } \text { ) Compreende a } \\
\text { escrita por extenso } \\
\text { e leitura de } \\
\text { números pelo }\end{array}$ \\
\hline
\end{tabular}




\begin{tabular}{|c|c|c|c|}
\hline & & $\begin{array}{l}\text { algebricamente; } \\
\text { escrita de } \\
\text { sequências } \\
\text { crescentes e } \\
\text { decrescentes; } \\
\text { comparação de } \\
\text { grandezas } \\
\text { numéricas; cálculo } \\
\text { de operações e } \\
\text { resolução de } \\
\text { problemas. }\end{array}$ & $\begin{array}{l}\text { aluno e em seguida } \\
\text { o aplicador lê o } \\
\text { número e o aluno } \\
\text { escreve } \\
\text { algebricamente. } \\
\left.2 .{ }^{\circ}\right) \text { Contagem } \\
\text { numérica: o aluno } \\
\text { escreve em ordem } \\
\text { crescente de dois } \\
\text { em dois números e } \\
\text { depois em ordem } \\
\text { decrescente de três } \\
\text { em três números. } \\
\left.3 .{ }^{\circ}\right) \text { Relação entre } \\
\text { maior/menor } \\
\text { sendo } \\
\text { apresentados } \\
\text { quatro parres de } \\
\text { números e ao } \\
\text { aluno circula o } \\
\text { maior de cada par. } \\
\left.4 .{ }^{\circ}\right) \text { As quatro } \\
\text { operaçóes } \\
\text { aritméticas } \\
\text { resolvidas pelos } \\
\text { alunos; } \\
5 .^{\circ} \text { ) Apresentação } \\
\text { oral dos cálculos e } \\
\text { o aluno escreve a } \\
\text { resolução; } \\
\left.6 .^{\circ}\right) \text { Resolução de } \\
\text { problemas por } \\
\text { escrito que devem } \\
\text { ser resolvidos. }\end{array}$ \\
\hline $\begin{array}{l}\text { Roteiro para } \\
\text { sondagem de } \\
\text { habilidades } \\
\text { matemáticas - } \\
\text { Coruja PROMAT, } \\
\text { 2or6. }\end{array}$ & $\begin{array}{l}\text { WEINSTEIN, M. } \\
\text { C. A. }\end{array}$ & $\begin{array}{l}\text { Voltado a } \\
\text { escolares de } 6 \text { a } 13 \\
\text { anos ou do } \\
\text { I. } 9 \text { ao } 5 . \text { o ano do } \\
\text { EF, constitui-se } \\
\text { em um roteiro de } \\
\text { sondagem das } \\
\text { habilidades } \\
\text { matemáticas. }\end{array}$ & $\begin{array}{l}\text { Identifica em } \\
\text { contexto escolar e } \\
\text { clínico as áreas de } \\
\text { defasagem e os } \\
\text { indicadores para } \\
\text { transtorno } \\
\text { específico de } \\
\text { aprendizagem em } \\
\text { Matemática e } \\
\text { discalculia. As } \\
\text { áreas avaliadas } \\
\text { são: representação }\end{array}$ \\
\hline
\end{tabular}




\begin{tabular}{|c|c|c|c|}
\hline & & & $\begin{array}{l}\text { de magnitude } \\
\text { numérica; } \\
\text { evocação de fatos } \\
\text { numéricos básicos } \\
\text { ou aritméticos; e } \\
\text { resolução de } \\
\text { problemas. }\end{array}$ \\
\hline $\begin{array}{l}\text { Coleção Avaliação } \\
\text { neuropsicológica } \\
\text { cognitiva. Vol. 3, } \\
\text { 20I2. }\end{array}$ & $\begin{array}{l}\text { SEABRA, A. G. et } \\
\text { al. }\end{array}$ & $\begin{array}{l}\text { O objetivo é } \\
\text { subsidiar a prática } \\
\text { da avaliação } \\
\text { neuropsicológica } \\
\text { cognitiva, fornecer } \\
\text { subsídios teóricos } \\
\text { e instrumentos } \\
\text { acompanhados dos } \\
\text { sumários de suas } \\
\text { qualidades } \\
\text { psicométricas e de } \\
\text { tabelas de } \\
\text { normatização que } \\
\text { possibilitam } \\
\text { interpretar os } \\
\text { desempenhos de } \\
\text { um indivíduo em } \\
\text { relação ao esperado } \\
\text { para seu nível de } \\
\text { desenvolvimento. }\end{array}$ & $\begin{array}{l}\text { No vol. } 3 \\
\text { "Avaliação } \\
\text { Neuropsicológica } \\
\text { Cognitiva: Leitura, } \\
\text { Escrita e } \\
\text { Aritmética", têm- } \\
\text { se I4 capítulos } \\
\text { divididos em: I) } \\
\text { Leitura e escrita; 2) } \\
\text { Competência } \\
\text { aritmética; e 3) } \\
\text { Estudos de caso. }\end{array}$ \\
\hline
\end{tabular}

Fonte: elaborado pelos autores

\section{DISCUSSÃO}

De fato, déficits no desenvolvimento das habilidades primárias da aprendizagem matemática levam a prejuízos significativos na aprendizagem das habilidades secundárias. Daí a importância de ampliar as pesquisas específicas sobre a avaliação matemática a fim 
de que sejam identificadas, precocemente, as lacunas e proporcionar intervenções que promovam o desenvolvimento das habilidades matemáticas preditoras a crianças que se encontrem em risco ou com dificuldades de aprendizagem matemática.

É notório que o comprometimento em qualquer destas etapas pode acarretar em dificuldades de aprendizagem que se diferem dos transtornos de aprendizagem, cuja discussão não é o objetivo deste presente estudo.

Hoje, no Brasil, o documento normativo que estabelece os conteúdos e competências essenciais a serem desenvolvidos nas etapas da Educação Básica é a Base Nacional Comum Curricular (BNCC). Quanto à área da Matemática, a BNCC divide as habilidades e competências em Ensino Fundamental Anos Iniciais e Ensino Fundamental Anos Finais. O EFAI corresponde do I. ${ }^{\circ}$ ao $5 . \stackrel{\circ}{\text { ano e }}$ aborda cinco unidades temáticas a serem desenvolvidas: Números; Geometria; Álgebra; Grandezas e Medidas e Probabilidade e Estatística, arcabouço para que outros estudos voltados à clientela das Séries Iniciais sejam aprofundados.

Esta pesquisa de revisão integrativa evidenciou e comprovou a carência de instrumentos cientificamente construídos diante das novas exigências traçadas pela BNCC sobre os conteúdos mínimos necessários a serem trabalhados nas séries iniciais do Ensino Fundamental disponíveis à população brasileira.

\section{CONSIDERAÇÕES FINAIS}

A aprendizagem matemática mostra-se desafiadora, sobretudo, nas Séries Iniciais do Ensino Fundamental quando os alicerces são erguidos para que as habilidades essenciais sejam embasadas. No entanto, é notório o baixo desempenho associado às dificuldades de escolares devido à falta de identificação, estímulo e intervenção no desenvolvimento das habilidades preditoras para o ensino da Matemática. Nosso país carece de mais estudos robustos que somem-se aos já existentes e pioneiros com o objetivo de elaborarem eficazes instrumentos validados à população brasileira e que identifiquem precocemente os déficits no percurso da aprendizagem matemática, bem como as lacunas deixadas nas Séries Inicias da Educação Básica para que, de fato, intervenções qualitativas sejam realizadas para que resultados quantitativos sejam cada vez mais alcançados no cenário educacional. 


\section{REFERÊNCIAS}

AVAliAÇÃO NACIONAL DA AlfabetizAÇÃO. Avaliação Nacional Da Alfabetização (ANA): Documento Básico. Brasília: Instituto Nacional de Estudos e Pesquisas Educacionais Anísio Teixeira, 2013. 20 p. ISBN 978-85-7863-027-o I. Disponível em: https://download.inep.gov.br/educacao_basica/saeb/2013/livreto_ANA_online.pdf. Acesso em: 02 set. 202I.

BASTOS, J. A. O cérebro e a matemática. São Paulo: Edição do Autor, 2008.

BRASIL. Lei n. 13.005 , de 25 de junho de 2014. Aprova o Plano Nacional de Educação PNE e dá outras providências. Diário Oficial da União: seção I, Brasília, DF, p. I, 26 jun. 2014. Disponível em: http://pne.mec.gov.br/i8-planos-subnacionais-de-educacao/543plano-nacional-de-educacao-lei-n-13-005-2014.

Acesso em: ro de jul. 2021.

BRASIL. Ministério da Educação. Base Nacional Comum Curricular (BNCC). Educação é a Base: Ensino Infantil e Ensino Fundamental. Brasília: Ministério da Educação, 2017.

BRASIL. Ministério da Educação. Secretaria de Alfabetização. PNA: Política Nacional de Alfabetização/ Secretaria de Alfabetização. Brasília: Ministério da Educação, 2019.

BRASIL. Ministério da Educação e Cultura. Instituto Nacional de Estudos e Pesquisas Anísio Teixeira (INEP). Relatório do Brasil no PISA 2018. Versão preliminar. Brasília: Ministério da Educação, 2019.

CORSO, L. V.; DORNELES, B. V. Avaliação da Matemática: competências numéricas e competências de base. In: SCICCHITANO, R. M. J.; CASTANHO, M. I. S. (org.). Avaliação psicopedagógica: recursos para a prática. Rio de Janeiro: Wark Editora, 2013.

DEHAENE, S.; COHEN, L. Towards an anatocomical and functional modelo of number precessing. Mathematical Cognition, v. I, n. I, p. 83-120, 1995.

DEHAENE, S. The number sense: How the mind creates mathematics. OUP USA, 2011.

DIAMOND, A. Executive functions. Annu Rev Psycho, v. 64, p. 135-68, 2013

DSM-5. Manual Diagnóstico e Estatístico de Transtornos Mentais: DSM-V/ (American Psychiatric Association). 5. ed. Porto Alegre: Artmed, 2014.

ERCOLE, F. F.; MELO, L. S. de; ALCOFORADO, C. L. G. C. Revisão integrativa versus revisão sistemática. Reme, v. I8, n. I, p. I-260, jan./mar. 2014. Disponível em: https://www.reme.org.br/artigo/detalhes/904. Acesso em: 30 nov. 2020. 
FANTE, V.V; HOFNHEIZ, G.C; MILNITSY, S.L; PAZ, F.R. Evidências de Validade do Subteste Aritmética do TDE-II: da Psicometria moderna à Neuropsicologia Cognitiva Revista Neuropsicologia Latinoamericana, vol. 8, núm. 2, 2oı6, pp. 16-26.

FIORANELI, R. C.; CASTRO-CANEGUIM, J. de F. Z.; CARMO, dos S. Habilidades matemáticas básicas em crianças do ensino fundamental: dados iniciais de sistematização de instrumento de avaliação. In: REUNIÃO ANUAL DA SOCIEDADE BRASILEIRA DE PSICOLOGIA, 4I, 20II, Belém/PA. Anais [...] Belém/PA, 20II. Resumos de Comunicação Científica.

NEVES, F. S das. O ensino da Matemática nas Séries Iniciais: dificuldades e desafios. Dissertação (Mestrado Profissional em Matemática) Universidade Federal de Alagoas. Instituto de Matemática, Maceió/AL, 2018. Disponível em: http://www.repositorio.ufal.br/bitstream/riufal/4384/I/O\%2oensino\%2ode\%2omatem\%

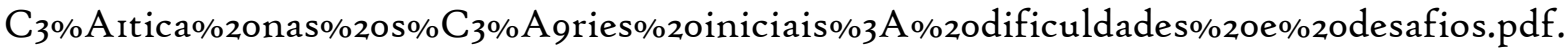
Acesso em: 22 ago. 2021.

NUNES, M. L.; COSTA, J. da C.; SOUZA, D. G. de. Entendendo o funcionamento do cérebro ao longo da vida. Porto Alegre: EdPUCRS, 2021.

PAZETO, T. C. B. de. Predição de leitura, escrita e matemática no ensino fundamental por funções executivas, na linguagem oral e habilidades iniciais de linguagem escrita na educação infantil. Tese (Doutorado em Distúrbios do Desenvolvimento) - Universidade Presbiteriana Mackenzie. São Paulo: 2016. Disponível em: http://tede.mackenzie.br/jspui/handle/tede/2899. Acesso em: 08 jul.202I.

PETRONZELLI, V.L.L. Políticas de avaliação da educação escolar brasileira: ensaios dialéticos sobre a literacia matemática no PISA/OCDE. Curitiba: Universidade Federal do Paraná, 2016. Disponível em: https://scholar.google.com.br/scholar?hl=ptBR\&as_sdt $=0 \% 2 \mathrm{C}_{5} \& \mathrm{q}=\mathrm{VERA}+\mathrm{LUCIA}+\mathrm{LUCIO}+\mathrm{PETRONZELLI}+\mathrm{POL} \% \mathrm{C}_{3} \% 8 \mathrm{DTICAS}$ \&btnG $=$ Acesso em: I4 set. 202I.

PICCOLI, L. et al. (org.). Pacto Nacional pela Alfabetização na Idade Certa PNAIC UFRGS: práticas de alfabetização, aprendizagem da matemática e políticas públicas. São Leopoldo: Oikos, 2018. E-book. 233 p. ISBN 978-85-7843-773-2. Disponível em: https://lume.ufrgs.br/handle/ror83/r86137. Acesso em: 08 jul. 2021.

PIRES, A.B.C; SIMÃO, A. N. P. de. Avaliação de crianças com indicação de dificuldades de aprendizagem pelo instrumento NEUPSILIN-Inf. Revista Psicopedagogia, São Paulo, vol.34 no.104, 2017 . Disponível em: http://pepsic.bvsalud.org/scielo.php?script=sci_arttext\&pid=So103-84862017000200005 Acesso em: 18 set. 2021.

PRATES, K. C. R.; LIMA, R. F. de; CIASCA, S. M. Estratégias de aprendizagem e sua relação com o desempenho escolar em crianças do Ensino Fundamental I. Revista 
Psicopedagogia, São Paulo, v. 33, n. ıо, p.19-27, 2016. Disponível em: http://pepsic.bvsalud.org/pdf/psicoped/v33nioo/o3.pdf.

Acesso em: 08 jul. 2021.

RODRIGUES, S. das D.; CIASCA, S. M. Tradução e adaptação para o português (brasileiro) da bateria de aferição de competências matemáticas (BAC -MAT). Revista Psicopedagogia, São Paulo, v. 37, n. 113, p. 168-182, 2020.

RUSSO, R. M. T. et al. Neuropsicopedagogia Clínica: introdução, conceitos, teoria e prática. Curitiba: Juruá Editora, 2015.

RUSSO, R. M. T. et al. Neuropsicopedagogia Institucional. Curitiba: Juruá Editora, 2018.

SANTANA, A. $\mathrm{N}$ de. Funções executivas e desempenho matemático em escolares. Dissertação (Mestrado em Psicologia Cognitiva) - Universidade Federal de Pernambuco, Recife, 2020. Disponível em: https://repositorio.ufpe.br/handle/123456789/38412? mode=full. Acesso em: o9 ago.2021.

SEABRA, A. G.; MARTINS, N. D.; CAPOVILlA, F. C. Avaliação neuropsicológica cognitiva: leitura, escrita e aritmética. São Paulo: Memnon, 2013. v. 3.

STEIN, L. M. Teste de desempenho escolar (TDE): Manual para aplicação e interpretação. São Paulo: Casa do Psicólogo; 1994.

VIAPIANA, V. F. et al. Evidências de Validade do Subteste Aritmética do TDE-II: da Psicometria à Neuropsicologia Cognitiva. Revista Neuropsicologia Latinoamericana, v. 8, n. 2, p. 16-26, 2016. Disponível em:

. Disponível em: https://repositorio.pucrs.br/dspace/handle/ro923/ı6078. Acesso em: 30 de ag. 2021.

VIAPIANA, Vanisa Fantes; GIACOMONI, Claudia Hofnheiz; STEIN, Lilian Milnitsy, FONSECA, Rochele Paz. Evidências de Validade do Subteste Aritmética do TDE-II: da Psicometria à Neuropsicologia Cognitiva. Revista Neuropsicologia Latinoamericana, vol. 8, no. 2, p. 16-26. 2016. Disponível em: https://repositorio.pucrs.br/dspace/handle/ı0923/ı6078. Acesso em: 30 de ag. 2021. 